\title{
Resin-Based Composite and LCU-related Factors Affecting the Degree of Cure. A Literature Review: Part 1. Resin-Based Composites
}

\author{
Aldossary Mohammed ${ }^{1}$, Santini Ario2* \\ MClinDent, University of Edinburgh, UK \\ 2 University of Medicine and Pharmacy Tirgu Mures, Romania
}

Keywords: polymerisation, bisphenol-A-glycidyl methacrylate, ethyleneglycol dimethacrylate

Received: 8 August 2015 / Accepted: 15 September 2015

\section{Introduction}

Resin-Based Composite (RBC) is widely used in Dentistry to restore anterior and posterior teeth. There have been many advances in RBCs development to improve their clinical success rate and overcome the many disadvantages of the first materials. These materials are cured by visible light, and light curing units have also undergone considerable development. Recently, bulk-fill composite materials were introduced to be placed in the cavity in bulk, claiming replacement of the traditional layering technique. In this paper an overview of RBCs, their composition and properties will be presented.

\section{Resin-Based Composites}

Resin-Based Composites became available to dentistry in the 1960's following the development of the first methacrylate-based polymer system by Bowen in 1962 .

The early RBCs were, in the main, used in the anterior region, where the color of amalgam was not desired. At that time, all materials were chemically cured. With the advent of photo-polymerization, Ultra-violet (UV) light curing systems superseded these and, in the late 1970's, the first report about a dental filling material that was cured with blue light in the visible range was published [1].

Effective dentine bonding agents became available at the beginning of the 1990's, and since then, composites have found increasingly broad use as a universal restorative material [2]. Furthermore, there has been a growing demand for aesthetic restorations, not only in the anterior region, but also increasingly in posterior teeth. This, in turn, has resulted in the quest for composite materials that offer improved physical, aesthetic, and handling properties. The advent of tooth whitening or bleaching has also resulted in the need for whiter shades of RBCs [3].

Composite materials are composed of polymerizable organic resin monomer, inorganic fillers, and photoinitia-

* Correspondence to: Ario Santin

E-mail: ariosantini@hotmail.com tors to initiate the polymerization reaction. Silane coupling agent is also added to bind the fillers to the matrix.

When polymerized, the monomers convert from a liquid phase to a highly cross- linked solid polymer. Polymerization is initiated by visible light. Typically the base monomer is a dimethacrylate; bisphenol-A-glycidyl methacrylate (Bis-GMA) or urethane dimethacrylate (UDMA). These are viscous materials and other less viscous dimethacrylates such as triethylene glycol dimethacrylate (TEGDMA), ethyleneglycol dimethacrylate (EGDMA), hydroxyethyl methacrylate (HEMA) or bisphenol-A-dimethacrylate (Bis-DMA) are usually incorporated to reduce the effect of its high viscosity [4-6]. A reduction in the viscosity of the material allows the incorporation of fillers [7].

\section{Fillers}

The presence of fillers has the advantage of enhancing the elastic modulus of the material, controlling thermal expansion, increasing wear resistance and reducing the polymerization shrinkage [8]. To achieve these advantages, it has been recommended that filler contents should be 60 to $87 \mathrm{wt} \%$ [9]. Typically, fillers are made from radiopaque barium or zinc glass and can be classified according to their size. Macrofill sized $(>10 \mu \mathrm{m})$ fillers were used in the early composite materials. These were not clinically successful because of their poor wear resistance, inadequate surface properties and difficulty in polishing and thus the aesthetics were impaired [10]. The use of microfill and nanofill sized fillers (1-5 $\mu \mathrm{m}$ and 1-100 nm respectively) produced RBCs with excellent polishability and better resistance to wear. However, they resulted in increased viscosity and exhibited high polymerization shrinkage.

In attempt to utilize the positive properties of the different filler sizes, hybrid particles were introduced [3]. They contained of a mixture of fillers with different mean particle sizes.

Spherical silicon dioxide fillers were only available previously. Currently, barium aluminium silicate glass is the widely used filler. In addition to glasses, other materi- 
als used as fillers have included quartz, zirconia and alumina [11-13].

Light-cured composite materials set via a free-radical polymerization reaction which gives clinicians sufficient time for handling the material prior to curing. The polymerization process relies on the presence of a photoinitiator in the RBC which is sensitive to the blue light of the LCU, and a co-initiator which does not absorb light but interacts with the photoinitiator to initiate the polymerization reaction $[14,15]$. On absorbing the light photons, the photoinitiator molecule becomes excited and forms free radicals which in turn trigger the polymerization reaction by converting the carbon to carbon double bond in the monomer molecules to the polymer network.

\section{Camphorquinone (CQ)}

The combination of camphorquinone (CQ) with a tertiary amine is still the most commonly used initiator system in the commercial visible light-activated dental resin materials [15-17].

The absorption spectrum of CQ ranges from 360 to 520 $\mathrm{nm}$ [2] with a narrow peak absorption of 465 to $470 \mathrm{~nm}$ in the blue wavelength range [18-21]. CQ has an intense yellow color which is apparent in the lighter shades of composite which have been developed for use on bleached teeth, $[18,22]$ thus resulting in a limitation to the use of CQ.

In an attempt to enhance efficiency, improve the compatibility of absorption and light source emission, and reduce the adverse impact of the colored components, alternatives to the CQ/amine system have been introduced $[8,20,23]$. The most frequently investigated and more commonly available alternative photoinitiators are 2,4,6- trimethylbenzoyl-diphenylphosphine oxide (TPO) and 1-phenyl-1, 2-propanedione (PPD), both of which have absorption peak near the UV region of the spectrum and will be discussed in the following Sections. Other alternatives such as bisacylphosphine oxide (Irgacure 819), [21,22] and poctyloxy-phenyl-phenyl iodonium hexafluoroantimonate (OPPI), [17] have been introduced with promising results. However, there is the need for further investigation, particularly since most of these studies used Quartz Tungsten Halogen (QTH) LCUs [22].

\section{Lucirin ${ }^{\circledR}$ (TPO) 2,4,6-trimethylbenzoyl- diphenylphosphine oxide}

TPO has an absorption range of 340-430 nm with a peak absorption at $390 \mathrm{~nm}$ [25]. Using TPO will facilitate the production of whiter shades of RBCs which have higher curing efficiency, higher degree of conversion [21,24,26,27].

\section{PPD (1-phenyl-1,2-propanedione)}

PPD can be used alone, or in combination, with CQ and at $410 \mathrm{~nm}$ has a shorter absorption peak than CQ $[15,18]$. Adding PPD to composite materials has also shown promising results such as a lower rate of polymerization stress without affecting the final degree of conversion
$[20,23,29]$. In similarity to TPO, the presence of PPD in a $\mathrm{RBC}$ has been found to result in less yellowing when compared to CQ/amine materials [15,18,21]. UU However, the converse was reported by Schneider [29] when PPD was used in higher concentration, providing evidence that PPD might be used, but with care regarding its concentration. Although PPD showed promising results, it seems its use still needs further investigation.

Most of the manufacturers of RBCs failed to state accurately the photo-initiators contained in their materials assuming that the majority contained CQ [30].

\section{Composite Consistency}

All RBC's in general can be classified also according to their consistency as viscous (packable/condensable) or flowable materials.

Viscous composite materials are used mainly in posterior teeth and have some modification to filler distribution by adding other types of particles such as fibers that tend to interlock and resist flow. To increase their strength and stiffness without affecting their ability to be condensed for better interproximal contact, the manufacturers avoided increasing the overall filler content [3]. When restoring a tooth in which a proximal contact with the adjacent tooth is required, the highly plastic consistency of viscous composite dictates that a matrix band be carefully contoured and wedged to obtain an acceptable proximal contact.

In flowable composites, viscosity is controlled by either decreasing the filler concentration [31,32] or by adding other modifying agents such as surfactants [3] and results in a material which allows easy placement in difficult cavities using a syringe. However, compared to viscous composites, they are inherently inferior in mechanical properties owing to the lower filler loading and a higher susceptibility to wear.

When introduced, flowable composites were claimed to act as a stress breaker producing restorations with better adaptation and therefore, reduced marginal microleakage $[32,34]$. However, clinical trials have not confirmed this to date [35-37] thus, these claims remain controversial [32].

Nowadays, flowable resins can be used in a variety of clinical procedures such as the restoration of small cavities, pit and fissure sealants, bases and liners and crown cementation $[31,33]$.

\section{Posterior Composite}

Use of RBCs in the posterior teeth has become more widely used in recent years for aesthetic reasons and because of concerns about the toxicity of mercury in amalgam [3840] Also, because amalgam does not bond to tooth structure, invasive cavity preparation for retention is required [41].

Good clinical success and longevity of the direct RBCs in posterior teeth have been reported in the literature [4] as good as above $90 \%$ for 2 to 5 years, [ 43 ] and over $70 \%$ 
at 10 years $[42,43]$. Failure of posterior composite restorations has been reported to be as a result of secondary caries and marginal leakage due to shrinkage, so it is important for the posterior composite to have good mechanical and physical properties and improved handling to increase their success rate [44].

\section{Effect of Incremental Thickness of Resin-Based Composite}

In cases of deep cavities, incremental placement of $2 \mathrm{~mm}$ thickness composite are recommended to reduce the polymerization shrinkage stress [45]. At these thicknesses sufficient light transmission occurs through to the bottom surface of the material allowing adequate curing throughout [46]. This was used as the gold standard [47-49]. However, curing a RBC incrementally carries the risk that voids and/or contamination may be incorporated between the layers. Bond failure between increments has also been reported and the technique can be time consuming, thus increasing the potential for further contamination [50].

\section{Bulk Fill Materials}

More recently, in an attempt to overcome some of the disadvantages of $2 \mathrm{~mm}$ incremental packing, bulk fill materials (BFMs) have been introduced to the market claiming that they would allow a $4 \mathrm{~mm}$ bulk placement in one layer while allowing sufficient polymerization (VOCO, 2010a, VOCO, 2010b, Vivadent, 2011, Dentsply, 2012, VOCO, 2013, Vivadent, 2014).

Two types of BFMs are available in the market, viscous and flowable. The flowable BFMs have been recommended for use in low load bearing areas and was aimed to place in one layer of $4 \mathrm{~mm}$ thickness to reduce polymerization stress. It is considered mandatory to cover flowable materials with a $2 \mathrm{~mm}$ layer of conventional RBC posteriorly [51,52] because their modulus elasticity and hardness are reduced [53]. The manufacturers of these materials stated some changes in composition in order to achieve the adequacy of bulk curing.

Ivoclar Vivadent introduced Tetric EvoCeram Bulk Fill as a viscous composite produced mainly for use in posterior teeth. They claimed two reasons why $4 \mathrm{~mm}$ increments could to be cured sufficiently. Firstly, by using two types of fillers with different mean particle sizes in order to match the refractive index of fillers to that of the monomer matrix for the ease of light transmission. Secondly, by using a patented photo- initiator (Ivocerin ), in addition to the standard systems, as a booster to make the polymerization faster and reliable in 10 seconds of curing by a dual peak LED LCU. In addition, they claimed the use of special shrinkage stress relievers to reduce the polymerization shrinkage.

Some manufacturers reduced the filler volume and increased the filler size (such as in X-tra base, X-tra fil and SureFil SDR $\left.{ }^{T M}\right)$. Consequently, the specific surface between fillers and organic matrix was lowered, thus reducing light scattering.
One example of the flowable materials is Smart Dentin replacement/ Shrinkage decreased resin (SDR) or SDR ${ }^{\mathrm{TM}}$ technology with modification to monomer (high weight modulator embedded in the center of monomer) to be less shrinkage.

Because of the decrease in the intensity of the light transmitting through the material, the main concern with these BFMs is to ensure sufficient polymerization at the deeper portions and the bottom by receiving enough light energy. Also, concerns regarding increased stress and deformation as a result of curing in large increments.

The potential disadvantages of BFMs can include possibility of more voids as placed in the mass of material, difficulty of making adequate contact areas, more stress as the entire mass polymerize at one time, and inadequate curing in the deepest part of the material [54].

In the literature, there are few studies evaluating some of the properties of the BFMs such as polymerization shrinkage, hardness, microleakage, marginal integrity, and creep deformation $[55,56]$.

An in vitro study by, [57] used two BFMs, Tetric EvoCeram Bulk Fill and X-tra base, to investigate the effect of curing time and light tip distance using a single peak LCU, and measured the light transmission by MARC and DC using FTIR. They concluded the validity of curing BFMs in $4 \mathrm{~mm}$ thick increments.

In one in vitro study, [58] X-tra fil (VOCO) was investigated when placed in bulk and incrementally and cured with two LED LCUs. No difference was found in Vickers Hardness between the two techniques $(P>0.05)$.

In another in vitro study [59], the mechanical properties, $\mathrm{VH}$ and DC, of SureFil SDR ${ }^{\text {TM }}$ was compared with other flowable composites when cured for 10, 20 and 40 seconds respectively. Variations between the materials when cured with different curing parameters was significantly different $(P<0.05)$. The recommendation was to cure the $4 \mathrm{~mm}$ bulk increments for 20 seconds when the total energy of $24 \mathrm{~J} / \mathrm{cm}^{2}$ was delivered to the top surface, which was higher than the manufacturers' recommendations.

A study by Alrahlah [60] used five BFMs including Tetric EvoCeram Bulk Fill and X-tra base. They used Elipar ${ }^{\mathrm{TM}}$ S10 $\left(1200 \mathrm{~mW} / \mathrm{cm}^{2}\right.$ x $\left.20 \mathrm{sec}\right)$ delivering $24 \mathrm{~J} / \mathrm{cm}^{2}$ which was higher than what recommended by the manufacturers. Their conclusion was in agreement with the manufacturer claims that the materials could be cured to an acceptable depth with increments ranging from 4 to $5 \mathrm{~mm}$.

Another study [30] investigated the light transmission and micromechanical properties of seven BFMs (three viscous and four flowable) using MARC compared to seven conventional composites (five viscous and two flowable). It was found that most of the BFMs tested were more translucent and the flowable BFMs showed the lowest mechanical properties including VH. However, in this study, a high top total energy was used $\left(34.6 \mathrm{~J} / \mathrm{cm}^{2}\right)$ and only one LED LCU [61]. Eight materials, four flowable bulk and four flowable conventional, including SDR and X-tra 
base were included in the study, which investigated the degree of conversion using FTIR after curing directly or after 24 hours. Although the BFMs' results were comparable to the conventional materials, there was variation between materials.

It was apparent that most of these studies were not following manufacturers recommendations regarding the least recommended total energy required. In addition, a variation from the manufacturers' recommended protocols, with respect both to LCUs and techniques were used.

\section{Reference}

1. Bassiouny MA. \& Grant AA. A visible light-cured composite restorative. Clinical open assessment. Br Dent J. 1978;145,327-30.

2. Santini A. Current status of visible light activation units and the curing of light- activated resin-based composite materials. Dent Update. 2010;37,214-227.

3. Ferracane JL. Resin composite-state of the art. Dent Mater. 2011;27,2938.

4. Ferracane JL. Current Trends in Dental Composites. Critical Reviews in Oral Biology \& Medicine. 1995;6,302-318.

5. Peutzfeldt A. Resin composites in dentistry: the monomer systems. Eur. J. Oral Sci. 1997;105,97-116.

6. Asmussen E.\& Peutzfeldt A. Influence of UEDMA BisGMA and TEGDMA on selected mechanical properties of experimental resin composites. Dent Mater DD . 1998.

7. da Silva EM., Poskus LT., Guimaraes JG.,et al. Influence of light polymerisation modes on degree of conversion and crosslink density of dental composites. J Mater. 2008

8. Cramer NB., Stansbury JW.\& Bowman CN. Recent advances and developments in composite dental restorative materials. J Dent Res. 2011;90,402-16.

9. Lohbauer U., Frankenberger R., Kramer N.\& Petschelt A. Strength and fatigue performance versus filler fraction of different types of direct dental restoratives. J Biomed Mater Res B Appl Biomater. 2006;76,114-20.

10. Turssi CP., Ferracane JL. \& Vogel K. Filler features and their effects on wear and degree of conversion of particulate dental resin composites. Biomaterials. 2005;26,4932-7.

11. Willems G., Lambrechts P., Braem M., Celis JP. \& Vanherle G. A classification of dental composites according to their morphological and mechanical characteristics. Dent Mater. 1992;8,310-9.

12. Gladys S., van Meerbeek B., Braem M., Lambrechts P., Vanherle G. Comparative physico-mechanical characterization of new hybrid restorative materials with conventional glass-ionomer and resin composite restorative materials. J Dent Res. 1997;76,883-94.

13. Arcis RW.,Lopez-Macipe A.,et al. Mechanical properties of visible lightcured resins reinforced with hydroxyapatite for dental restoration. Dent Mater. 2002;18.

14. Sim JS., Seol HJ., Park JK., et al. Interaction of LED light with co-initiatorcontaining composite resins: effect of dual peaks. J Dent. 2012;40,83642.

15. Stansbury JW. Curing dental resins and composites by photopolymerisation. J Esthet Dent. 2000;12,300-8.

16. Alvim HH., Alecio AC., Vasconcellos WA., et al. Analysis of camphorquinone in composite resins as a function of shade. Dent Mater. 2007;23,1245-9.

17. Shin DH.\& Rawls HR. Degree of conversion and color stability of the light curing resin with new photoinitiator systems. Dent Mater. 2009;25,10308.

18. Park YJ., Chae KH. \& Rawls HR. Development of a new photoinitiation system for dental light-cure composite resins. Dent Mater. 1999;15,1207.

19. Abate PF., Zahra VN.,Macchi RL. Effect of potopolymerisation variables on composite hardness. J Prosthet Dent. 2001;86,632-5.

20. Asmussen E.\& Peutzfeldt A. Influence of composition on rate of polymerisation contraction of light-curing resin composites. Acta Odontol Scand. 2002;60,146-50.

21. Neumann MG., Miranda WG., Jr. Schmitt CC., Rueggeberg FA.\& Correa IC. Molar extinction coefficients and the photon absorption efficiency of dental photoinitiators and light curing units. J Dent. 2005;33,525-32.

22. Arikawa H., Kanie T., Fujii K., et al. Optical and color stabilities of painton resins for shade modification of restorative resins. Dent Mater J.
2004;23,155-60.

23. Emami N. \& Soderholm KJ. How light irradiance and curing time affect monomer conversion in light-cured resin composites. Eur J Oral Sci. 2003;111, 536-42.

24. Arikawa H., Takahashi H., Kanie T. \& Ban S. Effect of various visible light photoinitiators on the polymerisation and color of light-activated resins. Dent Mater J. 2009;28,454-60.

25. Ilie N. \& Hickel R. Can CQ be completely replaced by alternative initiators in dental adhesives? Dent Mater J. 2008.;27,221-8.

26. Leprince JG., Hadis M., Shortall AC., et al. Photoinitiator type and applicability of exposure reciprocity law in filled and unfilled photoactive resins. Dent Mater. 2011;27,157-64.

27. Miletic V.\& Santini A. Micro-Raman spectroscopic analysis of the degree of conversion of composite resins containing different initiators cured by polywave or monowave LED units. J Dent. 2012;40,106-13.

28. Emami N.\& Soderholm KJ. Influence of light-curing procedures and photo- initiator/co-initiator composition on the degree of conversion of light- curing resins. J Mater Sci Mater Med. 2005;16,47-52.

29. Schneider LF., Pfeifer CS., Consani S., et al. Influence of photoinitiator type on the rate of polymerisation, degree of conversion, hardness and yellowing of dental resincomposites. Dent Mater. 2008;24, 1169-77.

30. Bucuta S.\& llie N. Light transmittance and micro-mechanical properties of bulk fill vs. conventional resin based composites. Clin Oral Investig. 2014;1-10.

31. Bayne SC., Thompson JY., Swift EJ. Jr., Stamatiades P., Wilkerson M. A characterization of first-generation flowable composites. J Am Dent Assoc. 1998;129,567- 77.

32. Ritter AV. Posterior composites revisited. J Esthet Restor Dent. 2008;20,57-67.

33. Bonilla ED., Yashar M.\& Caputo AA. Fracture toughness of nine flowable resin composites. J Prosthet Dent. 2003;89,261-7.

34. Frankenberger R., Kramer N., Pelka M.\& Petschelt A. Internal adaptation and overhang formation of direct Class II resin composite restorations. Clin Oral Investig. 1999;3,208-15.

35. Ernst CP., Canbek K., Aksogan K.\& Willershausen B. Two-year clinical performance of a packable posterior composite with and without a flowable composite liner. Clin Oral Investig. 2003;7,129-34.

36. van Dijken JW. \& Pallesen U. Clinical performance of a hybrid resin composite with and without an intermediate layer of flowable resin composite: a 7-year evaluation. Dent Mater. 2011;27,150-6.

37. Roggendorf MJ., Kramer N., Appelt A., Naumann Frankenberger R. Marginal quality of flowable $4-\mathrm{mm}$ base vs. conventionally layered resin composite. J Dent. 2011;39,643-7.

38. Brunthaler A., Konig F., Lucas T., Sperr W.\& Schedle A. Longevity of direct resin composite restorations in posterior teeth. Clin Oral Investig. 2003;7,63-70.

39. Burke FJ., Mchugh S., Hall AC., et al 2003. Amalgam and composite use in UK general dental practice in 2001. Br Dent J, 194, 613-8; discussion 609.

40. Lee MR., Cho BH., Son HH., Um CM. \& Lee IB. Influence of cavity dimension and restoration methods on the cusp deflection of premolars in composite restoration. Dent Mater. 2007;23,288-95.

41. Palin WM., Senyilmaz DP., Marquis PM. \& Shortall AC. Cure width potential for MOD resin composite molar restorations. Dent Mater. 2008;24,1083-94.

42. Knobloch LA., Kerby RE., Seghi R., Berlin JS. \& Clelland N. Fracture toughness of packable and conventional composite materials.J Prosthet Dent. 2002;88,307-13.

43. Opdam NJ., Bronkhorst EM., Roeters JM.\& Loomans BA. A retrospective clinical study on longevity of posterior composite and amalgam restorations. Dent Mater. 2007;23,2-8.

44. Beun S., Glorieux T., Devaux J., Vreven J.\& Leloup G. Characterization of nanofilled compared to universal and microfilled composites. Dent Mater. 2007;23,51-9.

45. Feilzer AJ., de Gee AJ.\& Davidson CL. Setting stress in composite resin in relation to configuration of the restoration. J Dent Res. 1987;66,16369.

46. Caughman WF., Rueggeberg FA.\& Curtis JW. Jr. Clinical guidelines for photocuring restorative resins. J Am Dent Assoc. 1995;126,12802,1284,1286.

47. Price RB., Derand T., Loney R. W. \& Andreou P. Effect of light source and specimen thickness on the surface hardness of resin composite. Am J Dent. 2002;15,47- 53.

48. Pilo R., Oelgiesser D.\& Cardash HS. A survey of output intensity and potential for depth of cure among light-curing units in clinical use. J Dent. $1999 ; 27,235-41$. 
49. Koupis NS., Martens LC.\& Verbeeck RM. Relative curing degree of polyacid-modified and conventional resin composites determined by surface Knoop hardness. Dent Mater. 2006;22,1045-50.

50. Flur YS., Hayoz S., Peutzfeldt A., Husler J.\& Lussi A. Depth of cure of resin composites: is the ISO 4049 method suitable for bulk fill materials? Dent Mater. 2012;28,521-8.

51. Abbas G., Fleming GJ., Harrington E., Shortall AC.\& Burke FJ. Cuspal movement and microleakage in premolar teeth restored with a packable composite cured in bulk or in increments. J Dent. 2003;31,437-44.

52. Burgess J.\& Cakir D. Comparative properties of low-shrinkage composite resins. Compend Contin Educ Dent. 2010;31SpecNo2,10-5.

53. Ilie N. \& Hickel R. Investigations on a methacrylate-based flowable composite based on the SDR technology. Dent Mater. 2011;27, 348-55.

54. Jun SK., Kim DA., Goo HJ.\& LEE HH. Investigation of the correlation between the different mechanical properties of resin composites. Dent Mater J, 2013;32,48-57.

55. Christensen GJ. Advantages and Challenges of Bulk-Fill Resins.Clinicians Report.2012;5,1-2

56. Safty S., Silikas N. \& Watts DC. Creep deformation of restorative resin- composites intended for bulk-fill placement. Dent Mater, 2012;28,92835.

57. Finan L., Palin WM., Moskwa N., Mcginley EL.\& Fleming GJ. The influence of irradiation potential on the degree of conversion and mechanical properties of two bulk-fill flowable RBC base materials. Dent Mater. 2013;29, no.8,906-912

58. Ilie N., Kessler A.\& Durner J. Influence of various irradiation processes on the mechanical properties and polymerisation kinetics of bulk fill resin based composites. J Dent. 2013;41,695-702.

59. Campodonico CE., Tantbirojn D., Olin PS. \& Versluis A. Cuspal deflection and depth of cure in resin-based composite restorations filled by using bulk, incremental and transtooth-illumination techniques. J Am Dent Assoc. 2011;142,1176-82.

60. Czasch P.\& Ilie N. In vitro comparison of mechanical properties and degree of cure of bulk fill composites. Clin Oral Investig. 2013;17,227-35.

61. Alrahlah A., Silikas N. \& Watts DC. Post-cure depth of cure of bulk fill dental resin-composites. Dent Mater. 2014;30,149-54.

62. Alshali RZ., Silikas N.\& SATTERTHWAITE JD. Degree of conversion of bulk-fill compared to conventional resin-composites at two time intervals. Dent Mater. 2013;29,e213-7. 